\title{
Strategies to enhance the production of pinoresinol and its glucosides by endophytic fungus (Phomopsis sp. XP-8) isolated from Tu-chung bark
}

\author{
Jing Zhu ${ }^{1,2}$, Lu Yan², Xiaoguang Xü ${ }^{2}$, Yan Zhang ${ }^{3}$, Junling Shi ${ }^{2 *}$, Chunmei Jiang ${ }^{2}$ and Dongyan Shao ${ }^{2}$
}

\begin{abstract}
To improve the production yield of (+)-pinoresinol (Pin), (+)-pinoresinol monoglucoside (PMG), and (+)-pinoresinol diglucoside (PDG), different methods were conducted, including co-culture with resveratrol-producing Alternaria sp. MG1 spores and addition of Tu-chung in a medium at the start of cultivation, ultrasound treatment ( $40 \mathrm{kHZ}, 10 \mathrm{~min}$ ) on 5-day culture, and addition of ethanol and sodium butyrate on Day 3, followed by cultivation for an additional period of 2 days. At the end of the cultivation period ( 5 days), the liquid phase was collected for product analysis. Cells were collected for the determination of gene expression levels and then used in bioconversion using resting cells for another period of 2 days. The liquid phase was measured to determine the output of the target products and the expression levels of the key genes related to the biosynthesis of these compounds. Consequently, co-culture with Alternaria MG1 and addition of Tu-chung bark in the medium efficiently increased Pin, PMG, and PDG production yield in the biosynthesis systems using potato dextrose broth medium and resting cells of Phomopsis sp. XP-8. The key genes related to the biosynthesis of these compounds were significantly upregulated. However, in the majority of cases, the addition of ethanol and sodium butyrate, and ultrasound treatment decreased the production yield of Pin, PMG, and PDG. The change in production yield was not consistently accompanied by a change in gene expression.
\end{abstract}

Keywords: Phomopsis sp. XP-8, Lignans, RT-qPCR, Co-culture

\section{Introduction}

Lignan is a type of polyphenol that is widely found in plants. Pinoresinol $[(+)-\mathrm{Pin}]$ is a simple lignan converted from 2 coniferyl alcohol molecules via the phenylpropanoid pathway followed by the lignan biosynthesis pathway. Many lignan compounds and their derivatives have been found to have novel biological functions, including antibacterial and anticancer activities. Pin exhibits a considerably stronger anti-inflammatory activity against human intestinal Caco-2 cells, compared with other tested plant lignans (During et al. 2012). (+)-Pin

\footnotetext{
*Correspondence: sjlshi2004@nwpu.edu.cn; sjlshi2004@aliyun.com ${ }^{2}$ Key Laboratory for Space Bioscience and Biotechnology, School of Life Sciences, Northwestern Polytechnical University, 127 Youyi West Road, Xi'an 710072, Shaanxi, China

Full list of author information is available at the end of the article
}

and its glycosylation derivatives, pinoresinol diglucoside $\left((+)\right.$-1-pinoresinol $4,4^{\prime}$-di- $O$ - $\beta$-D-glucopyranoside, PDG), have been identified as enterolactone precursors with preventive effects against breast cancer (HornRoss et al. 2001) and endometrial cancer (Gumma and Ramesh 2003). (+)-Pin has also exerted putative hypoglycemic effects via the inhibition of $\alpha$-glucosidase (Wikul et al. 2012). PDG has been found to exhibit various pharmacological functions against hypertension (Luo et al. 2010) and osteoporosis (Saleem et al. 2005). After dietary consumption, PDG can be converted to enterolignans by intestinal microflora (Xie et al. 2003). As such, it can potentially reduce the risk of breast cancer (Xie et al. 2013) and other hormone-dependent cancers (Adlercreutz 2002).

The demand for lignans, including PDG and Pin, has rapidly increased as therapeutic materials have been 
developed in recent years (Satake et al. 2013). Almost all lignans are still mainly produced by extraction from plant materials because of their complex biosynthesis pathway and the involvement of multiple steps and enzymes. However, extraction from plants is not suitable for the scale-up production of these compounds because of the long growth period required for plants and low production yield of these compounds in nature. Microbial fermentation is regarded as having the greatest potential to produce these compounds owing to its high efficiency, easy of regulation, fast bioconversion, and absence of seasonal limitations. The recombination of multiple genes for metabolic remodeling is currently regarded as the most efficient technique in producing original plant products. However, this method is difficult to implement for lignan production because multiple genes and steps are required in the biosynthesis pathway. Phomopsis sp. XP-8 is an endophytic fungus isolated from the bark of Tu-chung (Eucommia ulmoides Oliv.), a traditional hypotensor in Chinese herb medicine. Phomopsis sp. XP-8 can produce Pin, PDG, and (+)-pinoresinol monoglucoside (PMG) in submerged fermentation (Shi et al. 2012), mung bean solid medium, and bioconversion systems with resting cells (Zhang et al. 2015). As such, it shows potential in the production of these compounds without the need for genetic modification.

However, the current yield of Pin and PDG in Phomopsis sp. XP-8 is considerably low, failing to satisfy the requirements for scale-up production. In addition, few studies have been successfully conducted on the development of an endophyte as a commercial producer of biological molecules apart from secondary metabolites in plants. Many methods have been conducted to improve the secondary metabolite yield and productivity of endophytes, such as mutagenesis (Zhou et al. 2010), genetic transformations (Liu et al. 2013), optimization of fermentation parameters (Wang et al. 2014), elicitor/inhibitor addition (Venugopalan and Srivastava 2015), precursor feeding (Guerrabubb et al. 2012), use of adsorbent resins/solid supports (Luo et al. 2014; Singh et al. 2010), cocultivation and mixed fermentation (Kusari et al. 2011), and use of epigenetic modifiers (Brakhage 2013). Co-culture of different organisms, including plant and different microorganisms (Soliman and Raizada 2013; Ola et al. 2013), addition of sodium butyrate (Jeremy et al. 2012) and ethanol (Zhao et al. 2013), and ultrasound (Schläfer et al. 2000) treatment, can improve the production yield of lignans and other products related to the phenylpropanoid pathway.

In the present study, co-culture of Phomopsis sp. XP-8 and Alternaria sp. MG1, an endophytic fungus isolated from grape that can produce resveratrol via the phenylpropanoid pathway-like pathway, and co-culture of
Phomopsis sp. XP-8 and Tu-chung bark were employed to enhance the production yield of Pin, PMG, and PDG. Ultrasound treatment and addition of ethanol and sodium butyrate were also conducted. Previously developed liquid fermentation and the bioconversion system with Phomopsis sp. XP-8 resting cells was used (Zhang et al. 2015, 2016b). The expression of the key genes (4-coumarate: CoA ligase, 4CL; chalcone synthase, CHS; UDP-glucosyl transferase, GT) related to the biosynthesis of Pin, PMG, and PDG was determined, and the yield of these compounds was monitored accordingly. The present study provides useful information for further research on Phomopsis sp. XP-8 and the lignan biosynthesis pathway.

\section{Materials and methods \\ Microorganisms}

Phomopsis sp. XP-8 (CCTCC M 209291) and Alternaria sp. MG1 (CCTCC M 2011348) were used in the study. They were maintained at the China Center for Type Culture Collection (Wuhan, China).

\section{Preparation of fungal cells}

Phomopsis sp. XP-8 was prepared as seed cultures, and Alternaria sp. MG1 was prepared as spore suspensions for all experiments in the study. The seed cultures of Phomopsis sp. XP-8 were prepared in a liquid potato dextrose medium (PDB) by cultivating 5 colonies $(5 \mathrm{~mm}$ in diameter) formed in a 5-day potato dextrose agar (PDA) culture for 3 days at $28^{\circ} \mathrm{C}$ and $180 \mathrm{rpm}$ (Zhang et al. 2016b). Alternaria sp. MG1 was prepared as spore suspensions of $1 \times 10^{6}$ spores $/ \mathrm{mL}$ from the 5-day PDA (Che et al. 2016).

\section{Methods}

Five methods were employed in the study to evaluate their effects on the yield of target products directly after cultivation in a PDB medium and in the bioconversion systems with only glucose and resting cells. The expression levels of the key genes related to the biosynthesis of Pin, PMG, and PDG were also measured to indicate the possible mechanisms underlying these effects. The outline of each approach is indicated in Fig. 1 and detailed below.

In the co-culture method, a system was constructed using a PDB medium (100 mL in a $250 \mathrm{~mL}$ flask) with the Phomopsis sp. XP-8 seed culture (5\% inoculum size), together with the prepared Alternaria sp. MG1 spore suspension at the inoculum size of $1 \%$. The culture that was only inoculated with Phomopsis sp. XP-8 was also used as the control. After inoculation, cultivation was conducted for 5 days at $28^{\circ} \mathrm{C}$ and $180 \mathrm{rpm}$.

The Tu-chung bark method was employed by cultivating Phomopsis sp. XP-8 in the PDB medium with Tuchung bark added. To prepare the medium, $5 \mathrm{~g}$ Tu-chung 


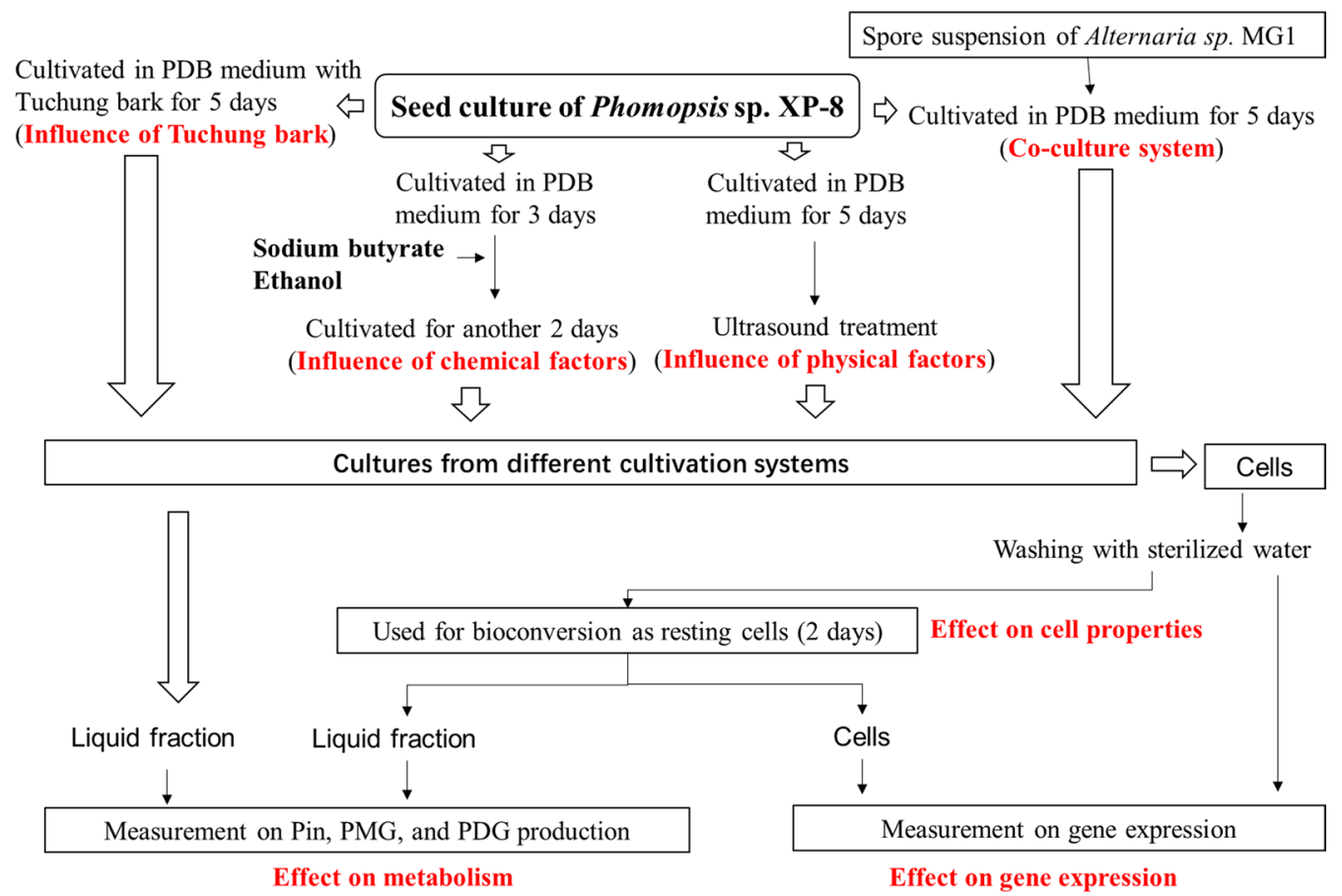

Fig. 1 Methods used in the study

bark was cut into small pieces (about $0.5 \mathrm{~mm}$ ) and then added into a PDB medium (100 mL in a $250 \mathrm{~mL}$ flask). After sterilization for $20 \mathrm{~min}$ at $121^{\circ} \mathrm{C}$, the PDB medium with Tu-chung bark was used to cultivate Phomopsis sp. XP-8 at the inoculum size of $5 \%$. The cultivation in PDB without Tu-chung bark was used as the control. The contents of the target products in the PDB medium containing Tu-chung bark but without Phomopsis sp. XP-8 was used as the control. All cultivations were conducted for 5 days at $28^{\circ} \mathrm{C}$ and $180 \mathrm{rpm}$.

The method involving the addition of chemicals was applied by cultivating Phomopsis sp. XP-8 in a PDB medium ( $100 \mathrm{~mL}$ in a $250 \mathrm{~mL}$ flask) at the inoculum size of $5 \%$. After cultivation for 3 days at $28{ }^{\circ} \mathrm{C}$ and $180 \mathrm{rpm}$, sodium butyrate and ethanol were added to the medium at final concentrations of $1 \mathrm{mmol} / \mathrm{L}$ and $3 \%(\mathrm{v} / \mathrm{v})$, respectively. The cultures were continuously cultivated for another period of $2 \mathrm{~d}$. The cultivation in PDB without any chemical addition was used as the control.

For the ultrasound method, the 5-day culture of Phomopsis sp. XP-8 was treated with ultrasound for $10 \mathrm{~min}$ at $40 \mathrm{kHz}$. Cultivation was conducted for 5 days in PDB (100 mL in $250 \mathrm{~mL}$ flask) at the inoculums size of $5 \%$ and under cultivation conditions of $28{ }^{\circ} \mathrm{C}$ and $180 \mathrm{rpm}$. The culture without ultrasound treatment was used as the control.

Subsequently, all cultures from different systems were separated as the liquid fraction and the cells by centrifugation at $5000 \times g$ for $10 \mathrm{~min}$ at $4{ }^{\circ} \mathrm{C}$. The liquid fraction was used to measure the production yield of Pin, PMG, and PDG. A portion of the cells was measure the gene expression levels of the key enzymes for the biosynthesis of these compounds. The residue cells were used as resting cells for bioconversion at the ratio of $10 \mathrm{~g}$ wet cells $/ 100 \mathrm{~mL}$ bioconversion system (distilled water, $\mathrm{pH}$ $7.0,15 \mathrm{~g} / \mathrm{L}$ glucose). Bioconversion for 2 days in a $250 \mathrm{~mL}$ flask at $28{ }^{\circ} \mathrm{C}$ and $180 \mathrm{rpm}$ was conducted. At the end of the bioconversion, the cells were collected by sterile filtration and then used for gene expression analysis. The liquid fraction was also collected to measure the production yield of Pin, PMG, and PDG.

\section{Analysis of key gene expression}

RNA extraction was performed using a commercial kit (Sangon Biotech Co., Ltd. Shanghai, China) in accordance with the protocol provided. The obtained RNA samples were qualitatively and quantitatively measured by using a NanoDrop 2000 spectrophotometer (Thermo Scientific, Waltham, USA) and by gel electrophoresis. cDNA was synthesized from $0.3 \mu \mathrm{g}$ of total RNA by using the OneStep gDNA Removal and cDNA Synthesis SuperMix kit (Transgen Biotech Co., Ltd. Beijing, China) in accordance with the protocol provided. The cDNA was conserved at $-80^{\circ} \mathrm{C}$ prior to use.

Five candidate genes were selected as reference genes from the transcriptome database of Phomopsis sp. XP-8 
(NCBI code: SRP100582, SRA code: PRJNA376069). These genes included $B$-TUB1 (encoding $\alpha$-tubulin), $B$ TUB2 (encoding $\alpha$-tubulin), Rps-24 (encoding ribosomal protein S24), $U B C$ (encoding ubiquitin-conjugating enzymes), and $\alpha$-ACTIN (encoding $\alpha$-actin). The internal reference genes were the same as those previously reported. All primers were designed using Primer 5.0 (http://www.premierbiosoft.com/primerdesign/index. html) with an amplicon length ranging from $100 \mathrm{bp}$ to $300 \mathrm{bp}$. Primer specificity was evaluated in silico by BLAST analysis and agarose gel electrophoresis. Amplification efficiency was calculated by dilution. The genes, primers, and efficiencies are listed in Table 1. The measurement of the expression levels of different candidate reference genes was conducted in the system containing Phomopsis sp. XP-8 cells in the PDB medium on Days 2, 3,4 , and 5 .

Real-time PCR was performed in 96-well plates on BioRad iCycler (Bio-Rad) using SYBR Green as the fluorophore. The PCR systems contains $1 \mu \mathrm{L}$ cDNA, $0.5 \mu \mathrm{M}$ forward and reverse primer, $10 \mu \mathrm{L} 2 \times$ EvaGreen Master Mix (Transgen), and 8.0 $\mu \mathrm{L}$ DNase-free water. Each sample was analyzed twice, and the no-template control for each primer was included in all real-time plates. Amplifications were performed under the following conditions: $95^{\circ} \mathrm{C}$ for $2 \mathrm{~min}, 40$ cycles of $95^{\circ} \mathrm{C}$ for $15 \mathrm{~s}, 60^{\circ} \mathrm{C}$ for $20 \mathrm{~s}$, and a final extension at $72^{\circ} \mathrm{C}$ for $2 \mathrm{~min}$. After comparing different genes (Noti et al. 2015), the best reference gene was selected using GeNorm ver. 3.5 (https://genorm. cmgg.be/) according to the $\mathrm{M}$ value after stepwise exclusion (Vandesompele et al. 2002).

The expression levels of the key genes related to the biosynthesis of Pin, PMG, and PDG (4CL, GT, CHS) were examined using the primers listed in Table 1 . The gene $U B C$ (available in NCBI SRA database with accession

Table 1 Primers used in gene expression analysis

\begin{tabular}{lll}
\hline Genes & Forward primer & Reverse primer \\
\hline UBC & CGT CGG AAC GAA TCA CAG & GCC ACC TAA ACG CAT ACC TC \\
& TA & \\
B-TUB1 & GGG AAC GAG GAG GTG & GGA TGC TGT CTG AAC TGG AG \\
& AAT AA & \\
B-TUB2 & TCG TGTTCG GAG ATA TGC & GAC GCG GTT GTA GTG TTT GA \\
& AG & \\
Rps24 & AAG CAA CGC AAG AAC & CTA TCA ACG CCC AGT CAT CA \\
a-ACtin & GGT AT ATTGT TGG GCG AAT & AAA CCA CAG CAT TGT TCC AC \\
4CL & GTG CAG CAA CTA CGTTCC & GCG ACC TGT AGA CCC TTC \\
& ATC CT & ACC TT \\
GT & CTG CTA AGC CAG GAC GGA & GAG TCG GAG GTG AAG TCG \\
& AGA GG & GAA GAA \\
CHS & CGCAGT GGT CCT GAG TAA & TCA ACA TCA AAG CCC AAG TC \\
& TG & \\
\hline
\end{tabular}

number of SRP060338) was used as the reference gene for all measurements because it was relatively stable compared with other tested reference genes. The relative quantification of mRNA expression was performed by normalizing the expression value transformed in relative copy numbers (obtained from $\mathrm{Cq}$ values and with efficiency considered).

\section{Measurement of target products}

Pin, PMG, and PDG were simultaneously determined by HPLC equipped with a detector and a Shimadzu Wondasil C18 $(250 \mathrm{~mm} \times 4.6 \mathrm{~mm})$ in accordance with a previously described method (Zhang et al. 2015). The temperature of the column was set to $30^{\circ} \mathrm{C}$. The mobile phase consisted of acetonitrile (chromatographic grade; Sigma-Aldrich) (solvent A) and $\mathrm{ddH}_{2} \mathrm{O}$ (solvent B). A multistep gradient was used for all analyses, as follows: 1-10 min, $90 \%(\mathrm{v} / \mathrm{v}) \mathrm{B} ; 10-20 \mathrm{~min}, 80 \% \mathrm{~B} ; 20-30 \mathrm{~min}$, $30 \% \mathrm{~B} ; 30-50 \mathrm{~min}, 90 \% \mathrm{~B}$. The flow rate was $1 \mathrm{~mL} / \mathrm{min}$, and the sample injection volume was $20 \mu \mathrm{L}$. The detection wavelengths were 226, 229, and $227 \mathrm{~nm}$ for Pin, PMG, and PDG, respectively. Standard Pin, PMG, and PDG (chromatographic grade; Sigma-Aldrich) were prepared in a methanol solution. The production yield of Pin, PMG, and PDG were calculated with reference to the results of the corresponding standards.

\section{Statistical analysis}

The Tuckey test was performed using the software SPSS (Version 18.0, IBM, Armonk, NY, USA) to evaluate the significance of variation among different treatments. The significance level was set at $p \leq 0.05$. The figures were performed using Origin 8.0 (Origin Software, Inc., OriginLab, USA) software.

\section{Results}

\section{Determination of suitable reference genes}

The statistical method GeNorm algorithm was used to identify the $M$ value of different reference genes (Vandesompele et al. 2002). The $M$ value represents the arithmetic average of pairwise variation. After stepwise exclusion, the software excludes the least stable gene (with the highest $M$ value) and recalculates the $M$ value. As shown in the results of GeNorm analysis (Fig. 2), $U B C$ and Rps 24 showed the lowest $\mathrm{M}$ values, indicating that they were the most stable reference genes used for measurement. $U B C$ was more stable than $R p s 24$ because the melting curve of Rps 24 was not unimodal in all tests (data not shown).

\section{Co-culture with Alternaria sp. MG1 spores}

Metabolite analyses indicated that co-culture induced a significant increase in Pin production yield by $156.87 \%$ 


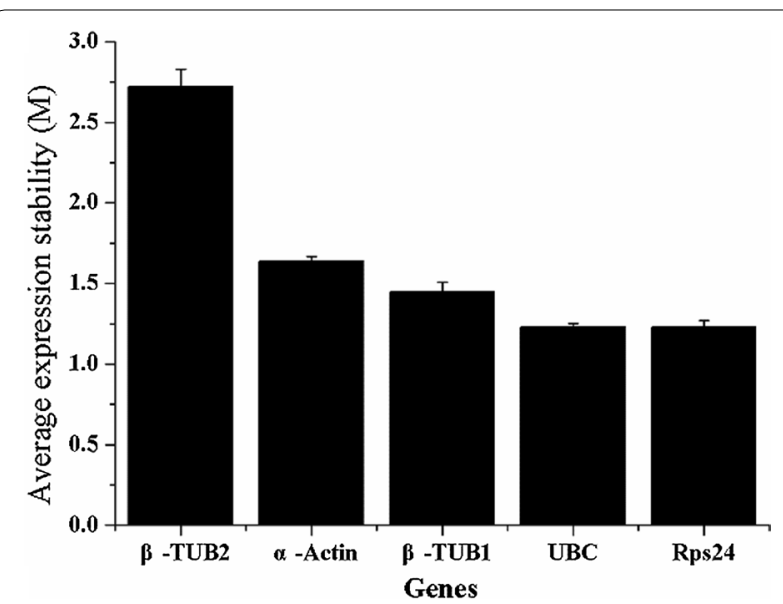

Fig. 2 Average expression stability value (M) of candidate reference gene expression in the PDB cultures of Phomopsis sp. XP-8
$(190.60 \mu \mathrm{g} / \mathrm{L})$ and PMG production yield by $17.89 \%$ $(628.42 \mu \mathrm{g} / \mathrm{L})$ but led to a decrease in PDG production yield in bioconversion in the PDB medium by $123 \%$ $(99.11 \mu \mathrm{g} / \mathrm{L})$ (Fig. 3a). This result was consistent with the 4.79-fold upregulation in the expression of $4 C L$ and the 0.61 - and 0.64-fold downregulation in the expression levels of CHS and GT, respectively (Fig. 3b).

In the bioconversion system with resting cells, co-culture with Alternaria sp. MG1 spores also showed significant increases in PMG yield by $24.51 \%(604.69 \mu \mathrm{g} / \mathrm{L})$ and PDG yield by $51.4 \%(469.41 \mu \mathrm{g} / \mathrm{L})$ but exhibited a decrease in Pin yield by $11.62 \%(6.55 \mu \mathrm{g} / \mathrm{L})$ (Fig. 3c). This result was consistent with the significant 32.15-, 3.75-, and 2.56-fold upregulation in the expression levels of $4 C L, G T$, and $C H S$, respectively.
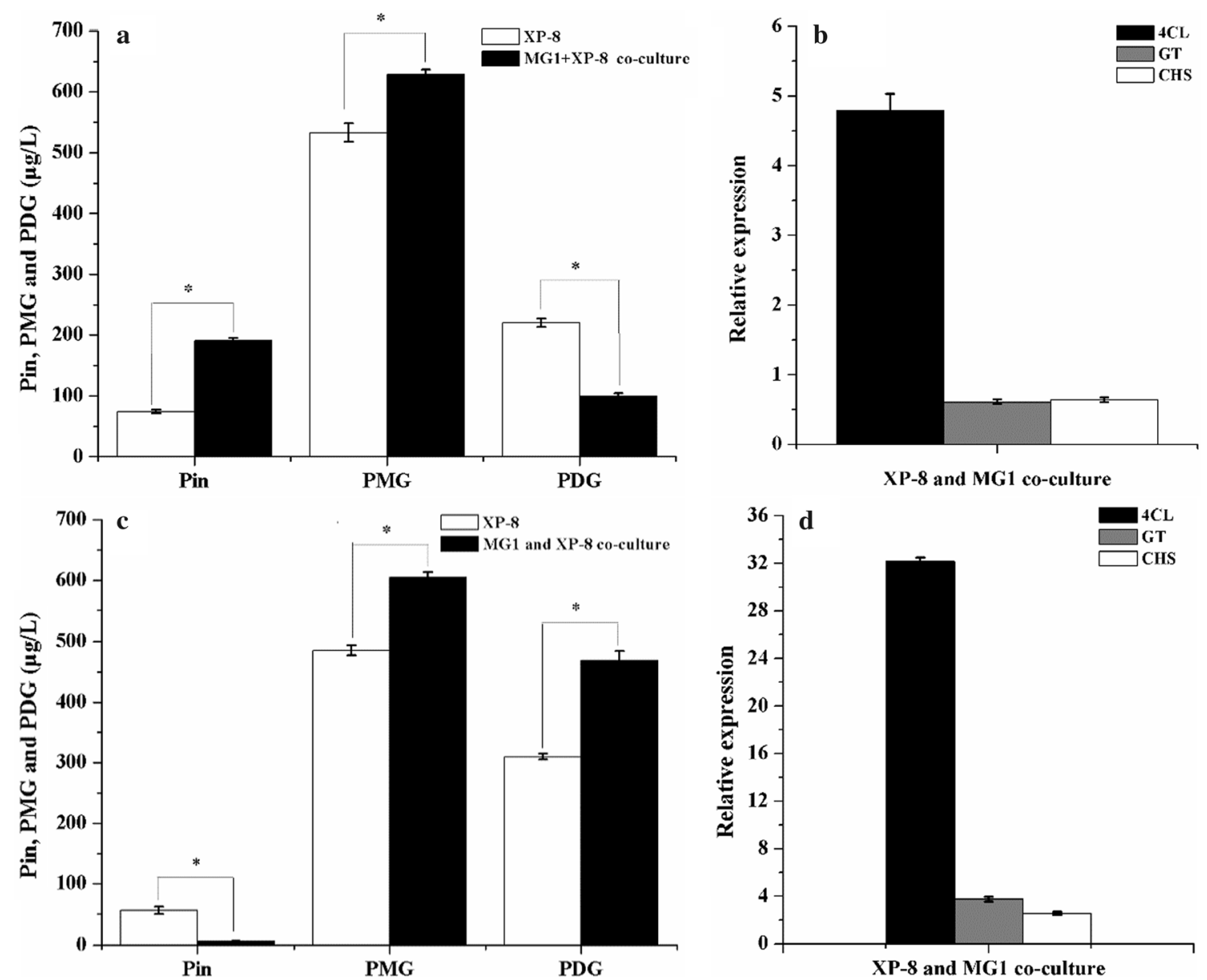

Fig. 3 Target product yield and gene expression in the co-culture method with Alternaria sp. MG1 spores using PDB medium (a, b) and the obtained resting cells $(\mathbf{c}, \mathbf{d})$ 

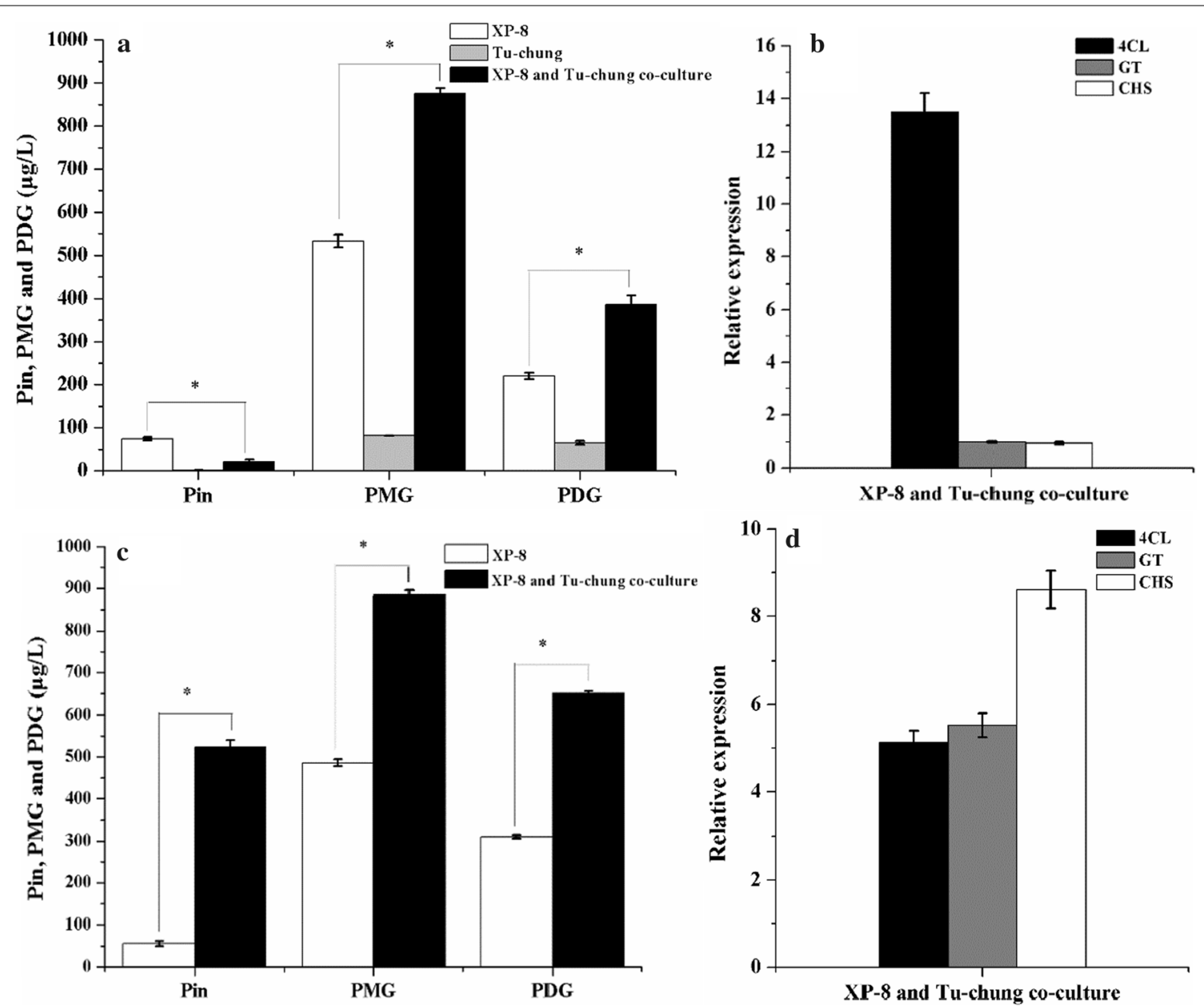

Fig. 4 Output levels of target products and expression levels of genes obtained using the method with PDB medium containing Tu-chung (a, $\mathbf{b}$ ) and the resting cells $(\mathbf{c}, \mathbf{d})$

\section{Addition of Tu-chung bark in the medium}

In the system using PDB, addition of Tu-chung bark in the medium increased the PDG and PMG production yield 1.75- and 1.64-fold, respectively, which corresponded to yields amounting to 385.98 and $875.51 \mu \mathrm{g} / \mathrm{L}$. However, the production of Pin was reduced (Fig. 4a). Correspondingly, the expression of 4CL was upregulated 13.5-fold, whereas the expression levels of GT and CHS were slightly downregulated 0.50 - and 0.96 -fold, respectively (Fig. 4b).

In the bioconversion systems using resting cells, the cells prepared in the medium containing Tu-chung bark led to significant increases in Pin, PMG, and PDG production yield by $829.48,88.18$, and $110.06 \%$, respectively; these increases correspond to yields amounting to 524.04, 884.76, and $651.27 \mu \mathrm{g} / \mathrm{L}$ (Fig. 4c). Corresponding to these results, the presence of Tu-chung bark in the medium resulted in the upregulated expression of the $4 \mathrm{CL}, \mathrm{GT}$, and CHS genes by 5.14-, 5.53-, and 8.61-, respectively, in the resting cells (Fig. $4 \mathrm{~d}$ ).

\section{Ultrasound induction}

In the PDB medium, the ultrasound treatment induced a 1.20-fold increase in PMG production yield, corresponding to $640.82 \mu \mathrm{g} / \mathrm{L}$. However, the production yield of Pin was reduced by $14.91 \%$, and PDG accumulation was not detected in the ultrasound-treated systems (Fig. 5a). Accordingly, the ultrasound treatment resulted in slight changes in the expression of $4 \mathrm{CL}$ and GT by 1.14- and 1.15 -fold, respectively, but caused a 0.62 -fold decrease in the expression of CHS (Fig. 5b).

In the bioconversion system using the resting cells prepared after ultrasound treatment, the production yield of Pin, PMG, and PDG was significantly decreased by 0 , 19.91 , and $26.18 \%$, respectively, relative to that using the resting cells prepared from the culture without ultrasound treatment. In addition, the ultrasound treatment 

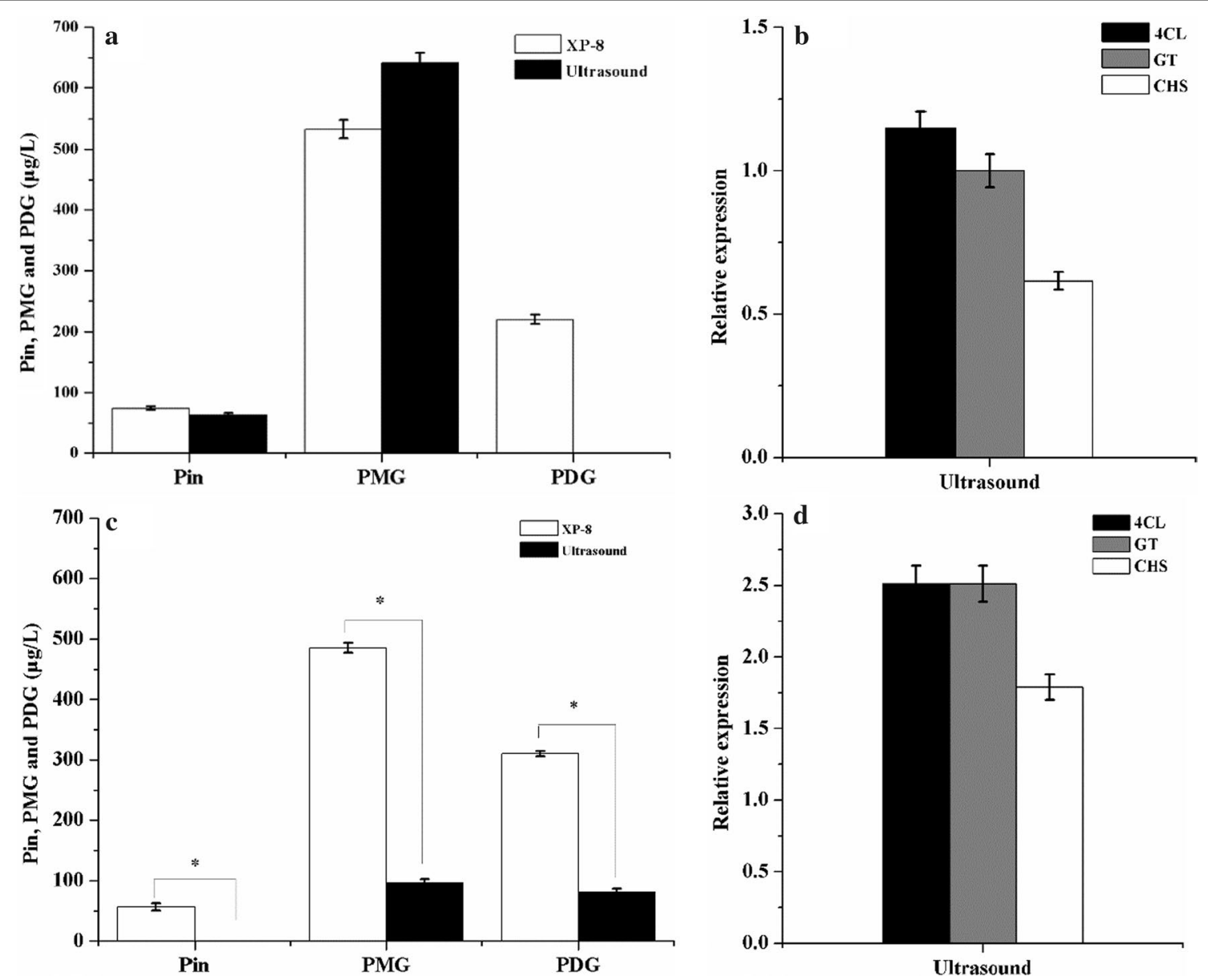

Fig. 5 Output of target products and gene expression levels obtained using ultrasound treatment in the systems with PDB medium (a, b) and the treated resting cells $(\mathbf{c}, \mathbf{d})$

led to the reduction in resting cells by half. (Fig. 5c). However, the upregulation in the expression levels of $4 \mathrm{CL}, \mathrm{GT}$, and CHS relative to the expression of UBC, corresponding to 2.51-, 2.50-, and 1.79-fold increases, respectively, was also induced by ultrasound treatment (Fig. 5d).

\section{Ethanol induction}

In the biosynthesis systems using PDB medium, ethanol induction on day 3 reduced the production yield of Pin, PMG, and PDG by $81.04,11.44$, and $100 \%$, respectively (Fig. 6a). However, 3.39-, 3.39-, and 1.79-fold increases in the expression levels of $4 \mathrm{CL}, \mathrm{GT}$, and CHS respectively, were found in the systems using ethanol induction (Fig. 6b). The results for the target products were not consistent with the results for the key genes. This inconsistency indicated that the presence of ethanol caused more significant downregulation in the expression levels of genes related to metabolism than those of the tested genes because UBC encodes the ubiquitin-conjugating enzyme.
In bioconversion systems using the resting cells obtained from the culture treated with ethanol, the output levels of Pin, PMG, and PDG were significantly reduced by 100,100 , and $72.62 \%$, respectively (Fig. $6 \mathrm{c}$ ). In accordance with these results, the expression levels of $4 \mathrm{CL}, \mathrm{GT}$, and CHS genes were significantly downregulated by $65-75 \%$ relative to the expression of the UBC gene (Fig. 6d).

Overall, compared with the liquid fraction of the coculture systems in PDB, the systems using resting cells showed a relatively higher upregulation in $4 C L, G T$, and $C H S$ and a considerably greater production yield in PDG, indicating that the biosynthesis of PDG was highly related to the upregulation in the expression levels of genes $G T$ and $C H S$.

\section{Induction with sodium butyrate}

In the biosynthesis systems containing PDB, induction with sodium butyrate decreased the output levels of Pin, PMG, and PDG by $63.98,14.61$, and 100\%, respectively, 

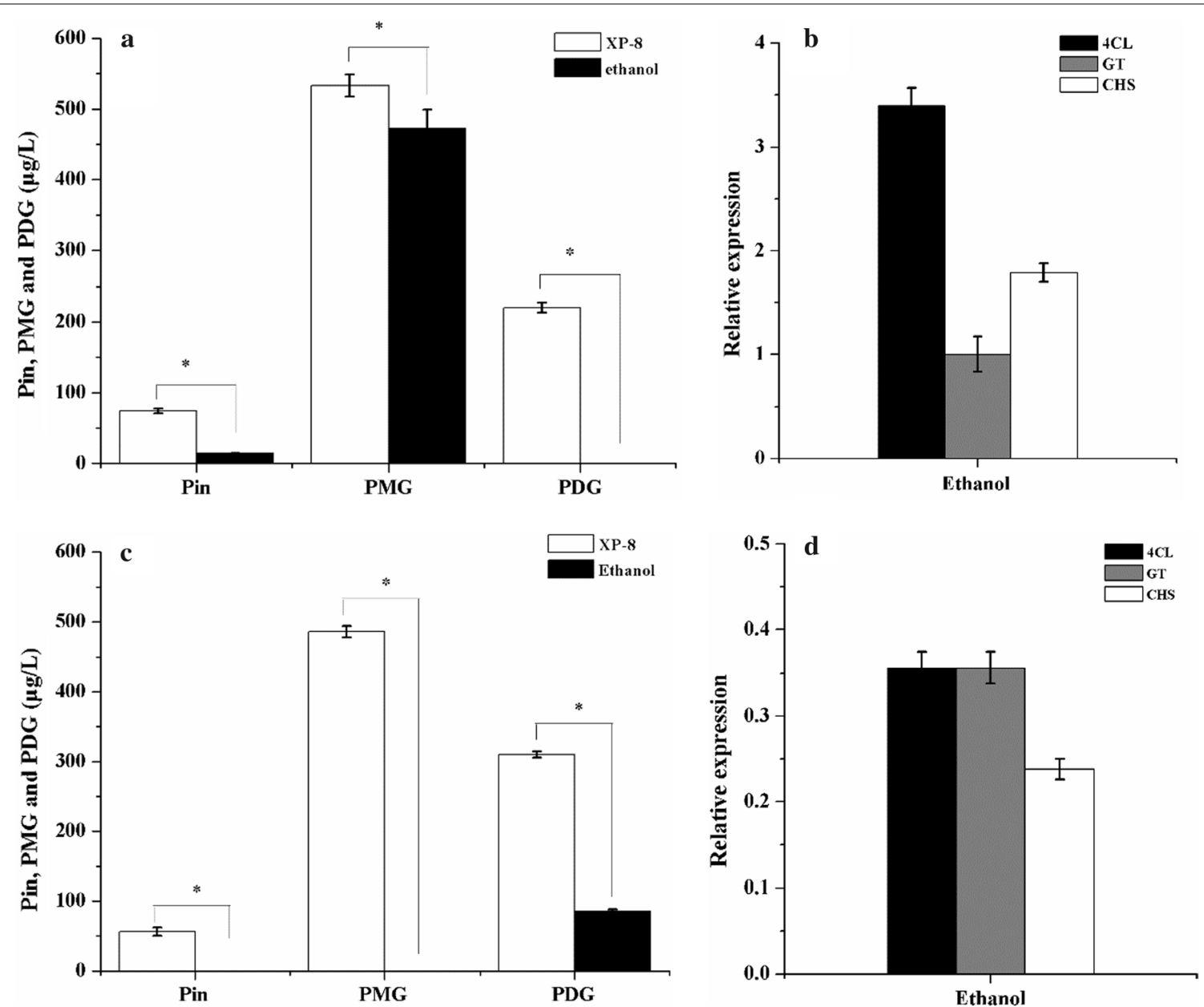

Fig. 6 Output levels of target products and expression levels of the genes obtained using ethanol induction in the systems containing the PDB medium $(\mathbf{a}, \mathbf{b})$ and resting cells $(\mathbf{c}, \mathbf{d})$

which correspond to 26.73, 455.12, and $0 \mu \mathrm{g} / \mathrm{L}$ (Fig. 7a). However, the expression levels of the key genes were slightly affected relative to the control without induction treatment (Fig. 7b).

In the bioconversion systems using resting cells, induction with sodium butyrate reduced the output levels of Pin, PMG, and PDG by $0,32.68$, and $23.81 \%$, respectively (Fig. 7c). However, the expression levels of $4 C L$ and GT remained upregulated 1.71 - and 1.71 -fold, respectively, relative to the expression of UBC although the expression of CHS was downregulated 0.64-fold when sodium butyrate was used in the induction (Fig. 7d).

\section{Discussion}

\section{Selection of reference genes for qRT-PCR analysis of Phomopsis sp. XP-8}

Gene expression profiling has become increasingly important in examining biological systems, particularly in elucidating complex signaling and metabolic pathways underlying developmental, biological, and cellular processes (Yeap et al. 2014). Among the widely used methods of measuring gene expression levels, quantitative realtime PCR ( $\mathrm{qRT}-\mathrm{PCR}$ ) is a robust method for assessing mRNA levels across different samples, with the advantages of accuracy, sensitivity, specificity, ability to quantify, and reproducibility (Schmidt and Delaney 2010). The variations are minimized by normalizing gene expression to the expression of one or more reference genes (Bustin et al. 2009). However, the use of inadequate reference genes may lead to errors in interpretation and misinterpretation of data on expression levels (Amil-Ruiz et al. 2013). Thus, appropriate reference genes are a prerequisite for qRT-PCR (Dankai et al. 2015). The stable reference genes in Phomopsis sp. XP-8 were first examined in this study although some traditional reference genes have been used for qRT-PCR data normalization in other studies on Phomopsis liquidambari (Xie and Dai 2015). In the current study, among the 5 traditional reference 

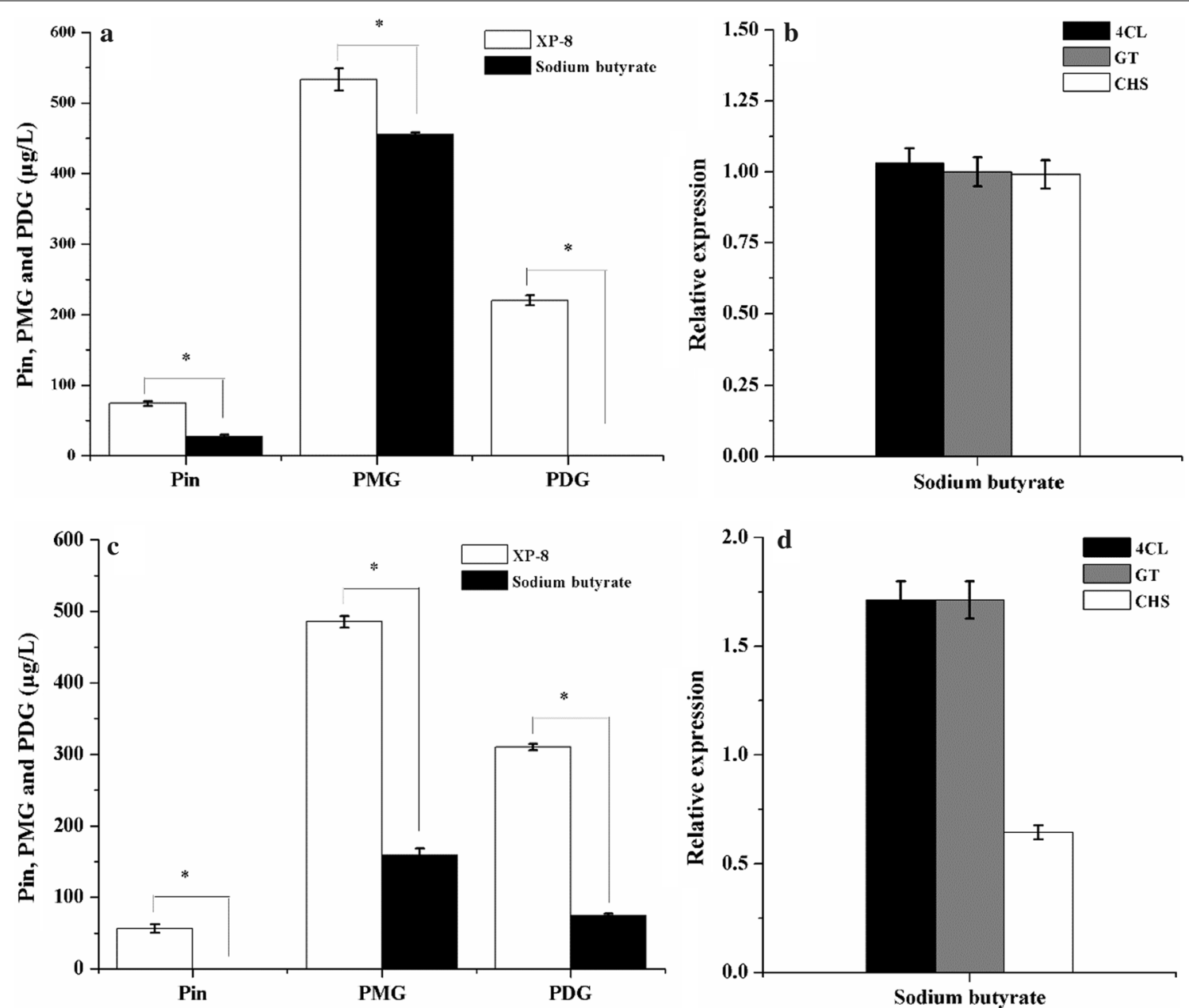

Fig. 7 Output levels of target products and expression levels of the genes obtained by sodium butyrate induction in the systems containing PDB $(\mathbf{a}, \mathbf{b})$ and resting cells $(\mathbf{c}, \mathbf{d})$

genes (B-TUB1, B-TUB2, Rps-24, UBC, and $\alpha$-ACTIN) tested, $U B C$ was identified as a stable expressed gene (Cho et al. 2014); however, multiple reference genes have been reported in other studies (Kong et al. 2015). This finding can facilitate further studies on the exploration of key genes related to secondary metabolites from Phomopsis sp. XP-8.

\section{Factors affecting the output of target products}

In the current study, many factors exerted influence on the output of target products. The presence of Tu-chung (the host plant of Phomopsis sp. XP-8) and Alternaria sp. MG1 (a resveratrol-producing endophytic fungus from grape) can increase the yield of target products, which is in accordance with the upregulation in the expression of key genes. Comparatively, the presence of Tu-chung bark led to the most significant increases in Pin, PMG, and PDG output, particularly in the biosynthesis system with resting cells. This result indicates the promotion of
Tu-chung on the secondary metabolites from Phomopsis sp. XP-8. In addition, the increase in output of the target products was also observed in the presence of Alternaria sp. spores, indicating that fungal and plant composition may exhibit similar properties. However, the addition of ethanol and sodium butyrate and the ultrasound treatment decreased the production yield of Pin, PMG, and PDG; however, an inconsistent change in gene expression was observed. This occurrence could be attributed to these chemical and physical factors, which could damage the viability of fungi.

In addition, the effect of each factor on the production yield of Pin, PMG, and PDG was not always consistent in the biosynthesis system with PDB medium that with resting cells. In our previous study, resting cell culture was found to improve resveratrol and the production yield of Pin (Zhang et al. 2013, 2016a). In other research, the resting cell culture systems were also developed to produce various compounds and to investigate 
the factors involved in the biosynthesis of bioactive substances (Marchand et al. 2008; Pandey et al. 2011).

\section{Effect of physical and chemical factors Ethanol}

The role of ethanol as a small-molecule elicitor altering the expression of silent (cryptic) secondary metabolite gene clusters is fully documented (Pettit 2011). Ethanol treatment has been found to increase the production yield of Huperzine A (51.89\% increment) by endophytic Colletotrichum gloeosporioides strain ES026 (Zhao et al. 2013). Marcoleta et al. (2011) demonstrated that ethanol addition promoted carotenogenesis in the yeast Xanthophyllomyces dendrorhous by increasing the expression levels of key genes, whereas glucose exerted a repressive effect.

However, in the current study, biomass production decreased in the presence of ethanol $(3 \%(\mathrm{v} / \mathrm{v}))$ in the PDB medium, indicating that ethanol exhibited cellular toxicity, as evidenced by the complete growth inhibition of Phomopsis sp. XP-8. Consequently, the output levels of the target products were reduced relative to that of the control. Therefore, ethanol may be associated with the availability of cell growth and the output of the target products of Phomopsis sp. XP-8. The growth of the endophyte $C$. gloeosporioides also decreased beyond a certain initial concentration of ethanol in the medium $(>3 \%$ $(\mathrm{v} / \mathrm{v})$ ) during the production of Huperzine A (Zhao et al. 2013). An increase in ethanol concentration beyond 5\% (v/v) led to a decrease in Huperzine A production yield because of the detrimental effect on fungal growth. In many other studies, $1 \%$ ethanol is the most favorable for fungal growth (Asthana et al. 1971; Zeuthen et al. 1988). Therefore, a further study on different ethanol concentrations should be conducted.

\section{Sodium butyrate}

Genomic analysis has demonstrated in recent years that some fungi possess essential gene clusters for the production of previously unobserved secondary metabolites. These genes are normally reduced or silenced under most of the conditions. Induction of these genes under stress or special conditions can improve the titers of known compounds or the production of new compounds. Epigenetic modifications in fungi have been used recently to produce new bioactive compounds (Wang et al. 2010; Scherlach and Hertweck 2009). Sodium butyrate has shown to efficiently induce the production of newly found compounds and enhance the production yield of known compounds by inhibiting histone deacetylases (HDAC) in fungi. This finding has been reported in the production of anti-infective cytosporones by the marine endophytic fungus Leucostoma persoonii (Shwab et al. 2007).
Sodium butyrate was also employed to enhance the production yield of cytosporones B (330\%), C (510\%), and E $(820 \%)$ by activating the genes related to biosynthesis of these secondary metabolites (Jeremy et al. 2012). Sodium butyrate was found to competitively inhibit class I HDAC and class II HDAC (Sekhavat et al. 2007). The inhibitory effect of sodium butyrate on Candida albicans was also related to the inhibition of chitin synthesis (Braun et al. 1987). About $25-100 \mathrm{mmol} / \mathrm{L}$ sodium butyrate inhibited germ tube formation by $40 \%$, whereas $100 \mathrm{mmol} / \mathrm{L}$ butyric acid almost completely inhibited germ tube formation (98\% inhibition) (Noverr and Huffnagle 2004). In the present study, $1 \mathrm{mmol} / \mathrm{L}$ sodium butyrate inhibited the growth of Phomopsis XP-8 but did not improve the output levels of Pin, PMG, and PDG. This occurrence could be attributed to the absence of association between HDAC and the biosynthesis of these compounds by using Phomopsis sp. XP-8.

\section{Ultrasound}

Mild intensity ultrasound has been found to affect enzymatic activity, cell membrane and microbial bioconversions (Chen et al. 2008), and secondary metabolite production (Wu and Lin 2002). Ultrasound treatment at intensities lower than $2 \mathrm{~W} / \mathrm{cm}^{2}$ and frequencies lower than $100 \mathrm{kHz}$ can increase the productivity of biological processes (Liu et al. 2012; Pitt and Ross 2003). Both responses to secondary metabolism elicitation and growth reduction caused by physical elicitors widely vary depending on the dose and time of exposure (Dewir et al. 2010; Kováčik et al. 2009). The optimal conditions for ultrasound exposure were reported as $2-5$ min (Rezaei et al. 2011; Wang et al. 2013). A longer exposure period significantly decreased the dry matter, viability, and productivity of target products by using fungi (Sulaiman et al. 2011). However, in the current study, ultrasound exposure $(40 \mathrm{kHz})$ for $10 \mathrm{~min}$ caused no significant increase the target products. This finding might be due to the long exposure time, causing damage to fungal cells. Another reason might be that the ultrasound treatment did not disturb the biosynthesis of these compounds. Ultrasound treatment was reported to cause no significant changes in the production yield of total phenolics (Russowski et al. 2013).

\section{Co-culture with other fungi}

Early co-cultures of different fungal species were conducted in solid-state media in which morphogenesis and metabolic changes were found at the leading edge of the fungal mycelia. The patterns of interaction between the different species were also observed in these co-culture systems. Co-cultures in solid-state media were employed between different fungi, bacteria, 
and protists (Chakraborty et al. 2017). In recent years, liquid-state media or mixed fermentation have also been used for the co-culture of different species of microorganisms, such as that observed in the natural processes occurring in wine processing (Alonso-delReal et al. 2017; Sáez et al. 2010). Co-culture of different bacteria, bacteria and fungi, and different fungi have shown great advantages in improving the manufacture of pharmaceutical products because they possess a similar pathway but complementary key genes for the biosynthesis of medicines (Bertrand et al. 2014; Beau et al. 2012).

Co-culture of the endophytic fungus Paraconiothyrium SSM001 with a bark fungus (Alternaria) caused a 3 -fold increase in Taxol production yield (Soliman and Raizada 2013). When SSM001 was pyramided with both the Alternaria endophyte along and another fungus (Phomopsis) observed to inhabit Taxus, was an 8-fold increase in fungal Taxol production yield from SSM001. Co-culture also induced an increase in the secondary metabolite production in the biosynthesis of the following: subenniatins A and B (Wang et al. 2013); fusaristatin A (Ola et al. 2013); enniatins A1, B1, and B (cyclic depsipeptides) and fusaristatin A-lipopeptide (Ola et al. 2013); podophyllotoxin (Baldi et al. 2010); stemphyperylenol (antifungal polyketide) (Chagas et al. 2013); and 13-oxo-9,11-octadecadienoic acid (oxylipin). In the present study, co-culture of Alternaria MG1 and Phomopsis XP-8 showed 2.57- and 1.18-fold increases in Pin and PMG production yield in the PDB medium and 1.25- and 1.52-fold increases in Pin and PMG production yield in resting cells. Mechanically, microbial communication may induce the expression of silent lignan gene clusters and thus lead to the production of Pin, PMG, and PDG.

In conclusion, co-culture with Alternaria MG1 and the addition of Tu-chung bark in the medium presented an effective method of increasing Pin, PMG, and PDG production yield in a biosynthesis system using PDB medium and that using the resting cells of Phomopsis sp. $\mathrm{XP}-8$. Correspondingly, the key genes related to the biosynthesis of these compounds, especially $4 C L$, were significantly upregulated. The study indicated a new method to improve the production yields of Pin, PMG, and PDG by Alternaria MG1.

\footnotetext{
Abbreviations

Pin: (+)-pinoresinol; PMG: (+)-pinoresinol monoglucoside; PDG: (+)-pinoresinol diglucoside; 4CL: 4-coumarate: $\mathrm{Co}$ A ligase; $\mathrm{CHS}$ : chalcone synthase; GT: UDP-glucosyl transferase; PDB: liquid potato dextrose medium; PDA: potato dextrose agar medium; Tu-chung: Eucommia ulmoides Oliv; B-TUB1: the gene encoding a-tubulin; $B$-TUB2: the gene encoding a-tubulin; Rps-24: the gene encoding ribosomal protein $S 24 ; U B C$ : the gene encoding ubiquitinconjugating enzymes; $\alpha$-ACTIN: the gene encoding $\alpha$-actin; BLAST: basic local alignment search tool; PCR: the polymerase chain reaction; CDNA: complementary DNA; SRA: sequence read archive; NCBI: National Center for
}

Biotechnology Information; mRNA: message RNA; HPLC: high performance liquid chromatography.

\section{Authors' contributions}

JS and JZ conceived and supervised the study; IZ and LY designed experiments and analyzed the data; $J Z, L Y$, and $X X$ performed the experiments; $Y Z$ provided help in the experimental design and data analysis; $\mathrm{CJ}$ and DS made manuscript revisions. All authors read and approved the final manuscript.

\section{Author details}

${ }^{1}$ School of Food Sciences, Xinyang Agriculture and Forestry University, 1 North Perimeter Road, Xinyang 464000, Henan, China. ${ }^{2}$ Key Laboratory for Space Bioscience and Biotechnology, School of Life Sciences, Northwestern Polytechnical University, 127 Youyi West Road, Xi'an 710072, Shaanxi, China. ${ }^{3}$ College of Food, Shihezi University, Road Beisi, Shihezi 832003, Xinjiang, China.

\section{Acknowledgements}

The authors want to thank Xiaoni Deng for the help in HPLC analysis and Key Laboratory for Space Bioscience and Biotechnology, School of Life Sciences, Northwestern Polytechnical University for providing all instruments used in the study.

\section{Competing interests}

The authors declare that they have no competing interests.

\section{Availability of data and materials}

Most of the data supporting our findings are included in the manuscript and the strains used in the study is available by asking the corresponding author.

\section{Consent for publication}

Not applicable.

\section{Ethics approval and consent to participate}

This article does not contain any studies with human participants or animals performed by any of the author.

\section{Funding}

The research was supported by the National Natural Science Foundation of China (Grant No. 31471718, 1701722), the National Key Technology R\&D Program (Grant No. 2015BAD16B02), the Modern Agricultural Industry Technology System (Grant No. CARS-30), the Key research and development plan of Shaanxi Province (Grant No. 2017ZDXL-NY-0304), the Universities key Scientific Research Project of Henan (Grant No. 18A550013), Shaanxi Provincial Postdoctoral Science Foundation (Grant No. 2017BSHEDZZ119) and the Scientific Project of Xinyang (Grant Number 150018).

\section{Publisher's Note}

Springer Nature remains neutral with regard to jurisdictional claims in published maps and institutional affiliations.

Received: 12 February 2018 Accepted: 3 April 2018

Published online: 16 April 2018

\section{References}

Adlercreutz H (2002) Phyto-oestrogens and cancer. Lancet Oncol 3(6):364-373. https://doi.org/10.1016/S1470-2045(02)00777-5

Alonso-del-Real J, Lairón-Peris M, Barrio E, Querol A (2017) Effect of temperature on the prevalence of Saccharomyces non cerevisiae species against a S. cerevisiae wine strain in wine fermentation: competition, physiological fitness, and influence in final wine composition. Front Microbiol 8:150. https://doi.org/10.3389/fmicb.2017.00150

Amil-Ruiz F, Garrido-Gala J, Blanco-Portales R, Folta KM, Muñoz-Blanco J, Caballero JL (2013) Identification and validation of reference genes for transcript normalization in strawberry (Fragaria $\times$ ananassa) defense responses. PLOS ONE 8(8):e70603. https://doi.org/10.1371/journal. pone.0070603 
Asthana H, Humphery AE, Moritz V (1971) Growth of yeast on methanol as the sole carbon substrate. Biotechnol Bioeng 13(6):923-929. https://doi. org/10.1002/bit.260130615

Baldi A, Farkya S, Jain A, Gupta N, Mehra R, Datta V, Srivastava AK, Bisaria VS (2010) Enhanced production of podophyllotoxins by co-culture of transformed Linum album cells with plant growth-promoting fungi. Pure Appl Chem 82(1):227-241. https://doi.org/10.1351/PAC-CON-09-02-09

Beau J, Mahid N, Burda WN, Harrington L, Shaw LN, Mutka T, Kyle DE, Barisic B, Olphen AV, Baker BJ (2012) Epigenetic tailoring for the production of antiinfective cytosporones from the marine fungus Leucostoma persoonii. Mar Drugs 10(4):762-774. https://doi.org/10.3390/md10040762

Bertrand S, Azzollini A, Schumpp O, Bohni N, Schrenzel J, Monod M, Gindro K, Wolfender JL (2014) Multi-well fungal co-culture for de novo metaboliteinduction in time-series studies based on untargeted metabolomics. Mol BioSyst 10(9):2289-2298. https://doi.org/10.1039/c4mb00223g

Brakhage AA (2013) Regulation of fungal secondary metabolism. Nat Rev Microbiol 11(1):21-32. https://doi.org/10.1038/nrmicro2916

Braun PC, Hector RF, Kamark ME, Hart JT, Cihlar RL (1987) Effect of cerulenin and sodium butyrate on chitin synthesis in Candida albicans. Can J Microbiol 33(6):546-550. https://doi.org/10.1139/m87-092

Bustin SA, Benes V, Garson JA, Hellemans J, Huggett J, Kubista M, Mueller R, Nolan T, Pfaffl MW, Shipley GL, Vandesompele J, Wittwer CT (2009) The MIQE guidelines: minimum information for publication of quantitative real-time PCR experiments. Clin Chem 55(4):611-622. https://doi. org/10.1373/clinchem.2008.112797

Chagas FO, Dias LG, Pupo MT (2013) A mixed culture of endophytic fungi increases production of antifungal polyketides. J Chem Ecol 39(10):13351342. https://doi.org/10.1007/s10886-013-0351-7

Chakraborty K, Thilakan B, Raola VK (2017) Antimicrobial polyketide furanoterpenoids from seaweed-associated heterotrophic bacterium Bacillus subtilis MTCC 10403. Phytochemistry 142:112-125. https://doi.org/10.1016/j. phytochem.2017.06.019

Che JX, Shi JL, Lu Y, Liu YL (2016) Validation of reference genes for normalization of gene expression by QRT-PCR in a resveratrol-producing entophytic fungus (Alternaria sp. MG1). AMB Express 6(1):106. https://doi. org/10.1186/s13568-016-0283-z

Chen B, Huang J, Wang J, Huang L (2008) Ultrasound effects on the antioxidative defense systems of Porphyridium cruentum. Colloids Surface B 61(1):88-92. https://doi.org/10.1016/j.colsurfb.2007.07.009

Cho Y, Ohm RA, Devappa R, Lee HB, Grigoriev IV, Kim BY, Ahn JS (2014) Transcriptional responses of the $B d t f 1$-deletion mutant to the phytoalexin brassinin in the necrotrophic fungus Alternaria brassicicola. Molecules 19(8):10717-10732. https://doi.org/10.3390/molecules 190810717

Combès A, Ndoye I, Bance C, Bruzaud J, Djediat C, Dupont J, Nay B, Prado S (2012) Chemical communication between the endophytic fungus Paraconiothyrium Variabile and the phytopathogen Fusarium oxysporum. PLoS ONE 7(20):e47313. https://doi.org/10.1371/journal.pone.0047313

Dankai W, Pongpom M, Vanittanakom N (2015) Validation of reference genes for real-time quantitative RT-PCR studies in Talaromyces marneffei. J Microbiol Meth 118:42-50. https://doi.org/10.1016/j.mimet.2015.08.015

Dewir YH, Chakrabarty D, Wu CH, Hahn EJ, Jeon WK, Paek KY (2010) Influences of polyunsaturated fatty acids (PUFAs) on growth and secondary metabolite accumulation in Panax ginseng C.A. Meyer adventitious roots cultured in air-lift bioreactors. S Afr J Bot 76(2):354-358. https://doi.org/10.1016/j. sajb.2009.10.008

During A, Debouche C, Raas T, Larondelle Y (2012) Among plant lignans, pinoresinol has the strongest antiinflammatory properties in human intestinal Caco-2 cells. J Nutr 142(10):1798-1805. https://doi.org/10.3945/ jn. 112.162453

Erik VB, Asad M, Marc DL (2010) Validation of reference genes for gene expression analysis in chicory (Cichorium intybus) using quantitative real-time PCR. BMC Mol Biol 11(1):1-12. https://doi.org/10.1186/1471-2199-11-15

Guerrabubb J, Croteau R, Williams RM (2012) The early stages of Taxol biosynthesis: an interim report on the synthesis and identification of early pathway metabolites. Nat Prod Rep 29(6):683. https://doi.org/10.1039/ c2np20021j

Gumma A, Ramesh A (2003) Phytoestrogen intake and endometrial cancer risk. J Natl Cancer I 95(15):1158-1164. https://doi.org/10.1093/jnci/djg015

Horn-Ross PL, John EM, Lee M, Stewart SL, Koo J, Sakoda LC, Shiau AC, Goldstein J, Davis P, Perez-Stable EJ (2001) Phytoestrogen consumption and breast cancer risk in a multiethnic population: the bay area breast cancer study. Am J Epidemiol 154(5):434-441. https://doi.org/10.1093/ aje/154.5.434

Jeremy B, Nida M, Burda WN, Lacey H, Shaw LN, Tina M, Kyle DE, Betty B, Alberto VO, Baker BJ (2012) Epigenetic tailoring for the production of anti-infective cytosporones from the marine fungus Leucostoma persoonii. Mar Drugs 10(4):762-774. https://doi.org/10.3390/md10040762

Kong F, Cao M, Sum P, Liu W, Mao Y (2015) Selection of reference genes for gene expression normalization in Pyropia yezoensis using quantitative real-time PCR. J Appl Phycol 27(2):1003-1010. https://doi.org/10.1007/ s10811-014-0359-6

Kováčik J, Grúz J, Bačkor M, Strnad M, Repčák M (2009) Salicylic acid-induced changes to growth and phenolic metabolism in Matricaria chamomilla plants. Plant Cell Rep 28(1):135-143. https://doi.org/10.1007/ s00299-008-0627-5

Kusari S, Košuth J, Čellárov AE, Spiteller M (2011) Survival-strategies of endophytic Fusarium solani against indigenous camptothecin biosynthesis. Fungal Ecol 4(3):219-223. https://doi.org/10.1016/j.funeco.2010.11.002

Liu R, Li W, Sun LY, Liu CZ (2012) Improving root growth and cichoric acid derivatives production in hairy root culture of Echinacea purpurea by ultrasound treatment. Biochem Eng J 60(2):62-66. https://doi. org/10.1016/j.bej.2011.10.001

Liu L, Wei YM, Zhou XW, Lin J, Sun XF, Tang KX (2013) Agrobacterium tumefaciens-mediated genetic transformation of the Taxol-producing endophytic fungus Ozonium sp. EFY21. Genet Mol Res 12(3):2913. https:// doi.org/10.4238/2013.august.12.7

Luo LF, Wu WH, Zhou YJ, Yan J, Yang GP, Ouyang DS (2010) Antihypertensive effect of Eucommia ulmoides Oliv. extracts in spontaneously hypertensive rats. J Ethnopharmacol 129(2):238-243. https://doi.org/10.1016/j. jep.2010.03.019

Luo H, Liu H, Cao Y, Xu D, Mao Z, Mou Y, Meng J, Lai D, Liu Y, Zhou L (2014) Enhanced production of botrallin and TMC-264 with in situ macroporous resin adsorption in mycelial liquid culture of the endophytic fungus Hyalodendriella sp. Ponipodef12. Molecules 19(9):14221-14234. https:// doi.org/10.3390/molecules190914221

Marchand P, Rosenfeld E, Erable B, Maugard T, Lamare S, Goubet I (2008) Coupled oxidation-reduction of butanol-hexanal by resting Rhodococcus erythropolis NCIMB 13064 cells in liquid and gas phases. Enzyme Microb Technol 43(6):423-430. https://doi.org/10.1016/j.enzmictec.2008.07.004

Marcoleta A, Niklitschek M, Wozniak A, Lozano C, Alcaino J, Baeza M, Cifuentes $V$ (2011) Glucose and ethanol-dependent transcriptional regulation of the astaxanthin biosynthesis pathway in Xanthophyllomyces dendrorhous. BMC Microbiol 11:190. https://doi.org/10.1186/1471-2180-11-190

Noti O, Vaudano E, Pessione E, Garciamoruno E (2015) Short-term response of different Saccharomyces cerevisiae strains to hyperosmotic stress caused by inoculation in grape must: RT-qPCR study and metabolite analysis. Food Microbiol 52:49-58. https://doi.org/10.1016/j.fm.2015.06.011

Noverr MC, Huffnagle GB (2004) Regulation of Candida albicans morphogenesis by fatty acid metabolites. Infect Immun 72(11):6206-6210. https:// doi.org/10.1128/iai.72.11.6206-6210.2004

Ola AR, Thomy D, Lai D, Brötz-Oesterhelt H, Proksch P (2013) Inducing secondary metabolite production by the endophytic fungus Fusarium tricinctum through coculture with Bacillus subtilis. J Nat Prod 76(11):2094-2099. https://doi.org/10.1021/np400589h

Pandey D, Singh R, Chand D (2011) An improved bioprocess for synthesis of acetohydroxamic acid using DTT (dithiothreitol) treated resting cells of Bacillus sp. APB-6. Bioresour Technol 102(11):6579-6586. https://doi. org/10.1016/j.biortech.2011.03.071

Pettit RK (2011) Smal-molecule elicitation of microbial secondary metabolites. Microb Biotechnol 4(4):471-478. https://doi. org/10.1111/j.1751-7915.2010.00196.x

Pitt WG, Ross SA (2003) Ultrasound increases the rate of bacterial cell growth Biotechnol Prog 19(3):1038-1044. https://doi.org/10.1021/bp0340685

Rezaei A, Ghanati F, Behmanesh M, Mokhtari-Dizaji M (2011) Ultrasoundpotentiated salicylic acid-induced physiological effects and production of Taxol in hazelnut (Corylus avellana L.) cell culture. Ultrasound Med Biol 37(11):1938-1947. https://doi.org/10.1016/j.ultrasmedbio.2011.06.013

Russowski D, Maurmann N, Rech SB, Fett-Neto AG (2013) Improved production of bioactive valepotriates in whole-plant liquid cultures of Valeriana glechomifolia. Ind Crop Prod 46(3):253-257. https://doi.org/10.1016/j. indcrop.2013.01.027 
Sáez JS, Lopes CA, Kirs VC, Sangorrín MP (2010) Enhanced volatile phenols in wine fermented with Saccharomyces cerevisiae and spoiled with Pichia guilliermondii and Dekkera bruxellensis. Lett Appl Microbiol 51(2):170. https://doi.org/10.1111/j.1472-765x.2010.02878.x

Saleem M, Kim HJ, Ali MS, Lee YS (2005) An update on bioactive plant lignans. Nat Prod Rep 22(6):696. https://doi.org/10.1039/b514045p

Satake H, Ono E, Murata J (2013) Recent advances in the metabolic engineering of lignan biosynthesis pathways for the production of transgenic plant-based foods and supplements. J Agric Food Chem 61(48):1172111729. https://doi.org/10.1021/jf4007104

Scherlach K, Hertweck C (2009) Triggering cryptic natural product biosynthesis in microorganisms. Org Biomol Chem 7(9):1753. https://doi.org/10.1039/ b821578b

Schläfer O, Sievers M, Klotzbücher H, Onyeche TI (2000) Improvement of biological activity by low energy ultrasound assisted bioreactors. Ultrasonics 38(1):711-716. https://doi.org/10.1016/s0041-624x(99)00132-8

Schmidt GW, Delaney SK (2010) Stable internal reference genes for normalization of real-time RT-PCR in tobacco (Nicotiana tabacum) during development and abiotic stress. Mol Genet Genomics 283(3):233-241. https://doi. org/10.1007/s00438-010-0511-1

Sekhavat A, Sun JM, Davie JR (2007) Competitive inhibition of histone deacetylase activity by trichostatin A and butyrate. Biochem Cell Biol 85(6):751758. https://doi.org/10.1139/007-145

Shi J, Liu C, Liu L, Yang B, Zhang Y (2012) Structure identification and fermentation characteristics of pinoresinol diglucoside produced by Phomopsis sp. isolated from Eucommia ulmoides Oliv. Appl Microbiol Biot 93(4):14751483. https://doi.org/10.1007/s00253-011-3613-8

Shwab EK, Jin WB, Tribus M, Galehr J, Graessle S, Keller NP (2007) Histone deacetylase activity regulates chemical diversity in Aspergillus. Eukaryot Cell 6(9):1656-1664. https://doi.org/10.1128/ec.00186-07

Singh MP, Leighton MM, Barbieri LR, Roll DM, Urbance SE, Hoshan L, Mcdonald LA (2010) Fermentative production of self-toxic fungal secondary metabolites. J Ind Microbiol Biot 37(4):335-340. https://doi.org/10.1007/ s10295-009-0678-9

Soliman SS, Raizada MN (2013) Interactions between co-habitating fungi elicit synthesis of Taxol from an endophytic fungus in host Taxus plants. Front Microbiol 4(1):3. https://doi.org/10.3389/fmicb.2013.00003

Sulaiman AZ, Ajit A, Yunus RM, Chisti Y (2011) Ultrasound-assisted fermentation enhances bioethanol productivity. Biochem Eng J 54(3):141-150. https://doi.org/10.1016/j.bej.2011.01.006

Vandesompele J, Preter KD, Pattyn F, Poppe B, Roy NV, Paepe AD, Speleman F (2002) Accurate normalization of real-time quantitative RT-PCR data by geometric averaging of multiple internal control genes. Genome Biol 3(7):0034. https://doi.org/10.1186/gb-2002-3-7-research0034

Venugopalan A, Srivastava S (2015) Enhanced camptothecin production by ethanol addition in the suspension culture of the endophyte, Fusarium solani. Bioresour Technol 188(z2):251-257. https://doi.org/10.1016/j. biortech.2014.12.106

Wang XR, Sena Filho JG, Hoover AR, King JB, Ellis TK, Powell DR, Cichewicz RH (2010) Chemical epigenetics alters the secondary metabolite composition of guttate excreted by an atlantic-forest-soil-derived Penicillium citreonigrum. J Nat Prod 73(5):942-948. https://doi.org/10.1021/np100142h

Wang F, Ma AZ, Guo C, Zhuang GQ, Liu CZ (2013) Ultrasound-intensified laccase production from Trametes versicolor. Ultrason Sonochem 20(1):118124. https://doi.org/10.1016/j.ultsonch.2012.05.003
Wang WJ, Li DY, Li YC, Hua HM, Ma EL, Li ZL (2014) Caryophyllene sesquiterpenes from the marine-derived fungus Ascotricha sp. ZJ-M-5 by the one strain-many compounds strategy. J Nat Prod 77(6):1367-1371. https:// doi.org/10.1021/np500110z

Wikul A, Damsud T, Kataoka K, Phuwapraisirisan P (2012) (+)-Pinoresinol is a putative hypoglycemic agent in defatted sesame (Sesamum indicum) seeds though inhibiting a-glucosidase. Bioorg Med Chem Lett 22(16):5215-5217. https://doi.org/10.1016/j.bmcl.2012.06.068

Wu J, Lin L (2002) Elicitor-like effects of low-energy ultrasound on plant (Panax ginseng) cells: induction of plant defense responses and secondary metabolite production. Appl Microbiol Biot 59(1):51-57. https://doi. org/10.1007/s00253-002-0971-2

Xie XG, Dai CC (2015) Degradation of a model pollutant ferulic acid by the endophytic fungus Phomopsis liquidambari. Bioresour Technol 179:35-42. https://doi.org/10.1016/j.biortech.2014.11.112

Xie LH, Akao T, Hamasaki K, Deyama T, Hattori M (2003) Biotransformation of pinoresinol diglucoside to mammalian lignans by human intestinal microflora, and isolation of Enterococcus faecalis strain PDG-1 responsible for the transformation of (+)-pinoresinol to (+)-lariciresinol. Chem Pharm Bull 51(5):508-515. https://doi.org/10.1248/cpb.51.508

Xie J, Tworoger SS, Franke AA, Terry KL, Rice MS, Rosner BA, Willett WC, Hankinson SE, Eliassen AH (2013) Plasma enterolactone and breast cancer risk in the nurses' health study II. Breast Cancer Res Treat 139(3):801-809. https:// doi.org/10.1007/s10549-013-2586-y

Yeap WC, Jia ML, Wong YC, Kulaveerasingam H (2014) Evaluation of suitable reference genes for qRT-PCR gene expression normalization in reproductive, vegetative tissues and during fruit development in oil palm. Plant Cell Tissue Organ 116(1):55-66. https://doi.org/10.1007/ s11240-013-0382-3

Zeuthen ML, Dabrowa N, Aniebo CM, Howard DH (1988) Ethanol tolerance and the induction of stress proteins by ethanol in Candida albicans. J Gen Appl Microbiol 134(5):1375-1384. https://doi. org/10.1099/00221287-134-5-1375

Zhang J, Shi J, Liu Y (2013) Bioconversion of resveratrol using resting cells of non-genetically modified Alternaria sp. Biotechnol Appl Bioc 60(2):236243. https://doi.org/10.1002/bab.1060

Zhang Y, Shi J, Gao Z, Yang WR, Jiang H, Che J, Liu Y (2015) Production of pinoresinol diglucoside, pinoresinol monoglucoside, and pinoresinol by Phomopsis sp. XP-8 using mung bean and its major components. Appl Microbiol Biot 99(11):4629. https://doi.org/10.1007/s00253-015-6491-7

Zhang Y, Shi J, Gao Z, Che J, Shao D, Liu Y (2016a) Comparison of pinoresinol diglucoside production by Phomopsis sp. XP-8 in different media and the characterisation and product profiles of the cultivation in mung bean. J Sci Food Agric 96(12):4015-4025. https://doi.org/10.1002/jsfa.7593

Zhang Y, Shi J, Liu L, Gao Z, Che J, Shao D, Liu Y (2016b) Bioconversion of pinoresinol diglucoside and pinoresinol from substrates in the phenylpropanoid pathway by resting cells of Phomopsis sp. XP-8. PLoS ONE 11 (2):e0137066. https://doi.org/10.1371/journal.pone.0137066

Zhao XM, Wang ZQ, Shu SH, Wang WJ, Xu HJ, Ahn YJ, Wang M, Hu X (2013) Ethanol and methanol can improve huperzine A production from endophytic Colletotrichum gloeosporioides ES026. PLoS ONE 8(4):e61777. https://doi.org/10.1371/journal.pone.0061777

Zhou X, Zhu H, Liu L, Lin J, Tang K (2010) A review: recent advances and future prospects of taxol-producing endophytic fungi. Appl Microbiol Biotechnol 86(6):1707-1717. https://doi.org/10.1007/s00253-010-2546-y 